\title{
Megalocornea-mental retardation syndrome: report of a new case
}

\author{
Ingeborg Barišić, Ivo Ligutić, Ljiljana Zergollern
}

\begin{abstract}
Megalocornea-mental retardation syndrome (MMR) is a rare autosomal recessive disorder presenting with megalocornea, mental and motor retardation, hypotonia, seizures, short stature, and characteristic dysmorphic traits (MIM 249310). We present a new case in order to delineate with more accuracy the typical phenotype.

(f Med Genet 1996;33:882-883)
\end{abstract}

Key words: megalocornea; mental retardation; Neuhäuser syndrome.

The proband is the second child of healthy, non-consanguineous parents. The neonatal period was complicated by convulsions and phenobarbital was introduced.

We examined the patient at the age of 2 years. Her length was $76 \mathrm{~cm}(-3 \mathrm{SD})$, weight $8250 \mathrm{~g} \mathrm{(}-3 \mathrm{SD})$, and $\mathrm{OFC} 48 \mathrm{~cm}$ (50th centile). Dysmorphic traits such as mild frontal bossing, large eyes with a slight antimongoloid slant and small epicanthic folds, depressed nasal base, short philtrum, long upper lip with downward slanting corners, and micrognathia were noted (fig 1). Ophthalmological examination showed megalocornea with corneal diameters of $13 \mathrm{~mm}$ without other ocular abnormalities. The heart, lungs, liver, and spleen were normal. Mild joint hyperlaxity and kyphoscoliosis were present. Of slender build and markedly hypotonic, she was not able to stand or walk without support. She had undeveloped speech, stereotypic hand movements, poor appetite, and difficulty in swallowing solid

Received 22 December 1995 Revised version accepted for publication 18 March 1996

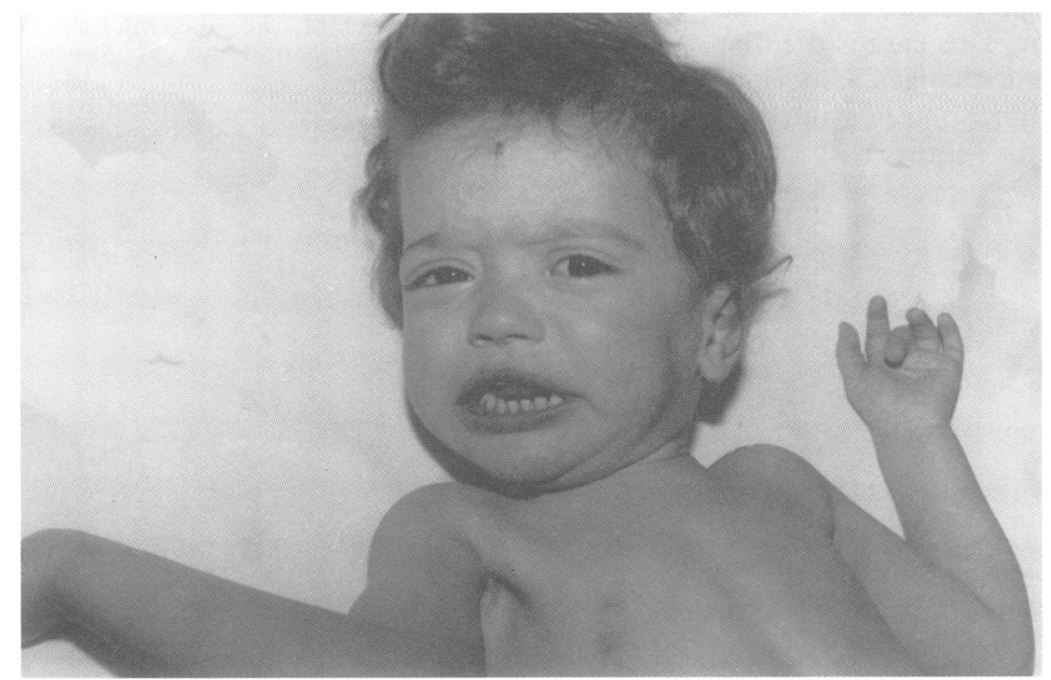

Figure 1 Facial features of the patient with MMR syndrome: antimongoloid eye slant, mild epicanthus, depressed nasal bridge, short philtrum, long upper lip with downward slanting corners, and small mandible. food. On psychological testing at this time her development was equivalent to 8-9 months.

All laboratory examinations performed were normal. EEG showed slow baseline activity and auditory evoked potentials showed delayed brainstem conduction. On magnetic resonance imaging of the brain, symmetrical delay of myelination in the parieto-occipital regions was observed. The karyotype was $46, \mathrm{XX}$ (prometaphase chromosomes).

Megalocornea-mental retardation syndrome was first reported by Neuhäuser et al in 1975 . Megalocornea, psychomotor retardation, and hypotonia are considered to be major clinical manifestations of MMR syndrome. ${ }^{2}$ Although descriptions of sporadic cases include discordant findings concerning facial dysmorphic features, some traits such as frontal bossing (83\%), antimongoloid eye slant $(64 \%)$, epicanthus $(77 \%)$, open mouth appearance $(92 \%)$, high/narrow palate $(60 \%)$, and small chin $(82 \%)$ appear in the majority of reports making the diagnosis in the presence of major diagnostic signs likely. Among central nervous system symptoms, clumsiness and retardation of speech development are particularly often reported (table 1$) \cdot{ }^{1-4}$

Various clinical features present in patients reported so far raise questions regarding the variable expressivity as opposed to aetiological heterogeneity of this syndrome. Verloes et $a l^{4}$ proposed a clinical classification into five subtypes. Our patient has typical features of and bears most similarity to type 1 , but does not have iris hypoplasia which is required for inclusion in this group. We think that the variable extent of ocular involvement is probably the expression of the same developmental eye defect and therefore should not be taken as a discriminating criterion for classification. Growth retardation cannot be a discriminative feature for type 2 as proposed, because it is present in about half of the patients belonging in different subgroups.

The number of cases reported so far is, in our opinion, too small to permit reliable classification into clinical or aetiological subgroups. Additional reports are needed to delineate the phenotype allowing perhaps the recognition of specific phenotypic/genotypic subtypes and in this way helping diagnosis and family counselling in this rare condition.

1 Neuhäuser GE, Kaveggia G, France TD, et al. Syndrome of mental retardation, seizures, hypotonic cerebral palsy and megalocorneae, recessively inherited. $Z$ Kinderheilkd 1975 120:1-18.

2 Santolaya JM, Grijalbo A, Delgado A, et al. Additional case of Neuhäuser megalocornea and mental retardation syndrome with congenital hypotonia. Am $f$ Med Genet syndrome with

3 Grønbech-Jensen $M$. Megalocornea and mental retardation syndrome: a new case. Am $\mathcal{F}$ Med Genet 1989;32:468-9. 
Table 1 Clinical manifestations in patients with MMR syndrome

\begin{tabular}{|c|c|c|c|c|}
\hline Clinical manifestations & Patient & $\begin{array}{l}\text { Published } \\
\text { reports }\end{array}$ & Total & $\%$ \\
\hline $\operatorname{Sex}(M: F)$ & $\mathrm{F}$ & $13: 10$ & $13: 11$ & \\
\hline Mental retardation & + & $23 / 23$ & $24 / 24$ & 100 \\
\hline Motor retardation & + & $23 / 23$ & $24 / 24$ & 100 \\
\hline Short stature & + & $9 / 23$ & $10 / 24$ & 42 \\
\hline \multicolumn{5}{|l|}{ Ocular } \\
\hline Megalocornea & + & $21 / 23$ & $22 / 24$ & 92 \\
\hline Iris hypoplasia & - & $6 / 22$ & $6 / 23$ & 26 \\
\hline Iridodonesis & - & $4 / 22$ & $4 / 23$ & 17 \\
\hline Refractive error & - & $7 / 15$ & $7 / 16$ & 44 \\
\hline Other & - & $6 / 21$ & $6 / 22$ & 27 \\
\hline \multicolumn{5}{|l|}{ Neurological } \\
\hline Hypotonia & + & $21 / 23$ & $22 / 24$ & 92 \\
\hline Spastic diplegia & - & $2 / 19$ & $2 / 20$ & 10 \\
\hline Ataxia & & $4 / 15$ & $4 / 15$ & 27 \\
\hline Clumsiness & + & $8 / 9$ & $9 / 10$ & 90 \\
\hline Abnormal movements & + & $4 / 11$ & $5 / 12$ & 42 \\
\hline Seizures/abnormal EEG & + & $10 / 23$ & $11 / 24$ & 46 \\
\hline Speech development retardation & + & $10 / 10$ & $11 / 11$ & 100 \\
\hline $\mathrm{ADD}$ & - & $6 / 13$ & $6 / 14$ & 43 \\
\hline \multicolumn{5}{|l|}{ Craniofacial } \\
\hline Microcephaly & - & $7 / 23$ & $7 / 24$ & 29 \\
\hline Macrocephaly & - & $5 / 23$ & $5 / 24$ & 21 \\
\hline Frontal bossing & + & $14 / 17$ & $15 / 18$ & 83 \\
\hline Antimongoloid slant & + & $6 / 10$ & $7 / 11$ & 64 \\
\hline Hypertelorism/telecanthus & - & $7 / 13$ & $7 / 14$ & 50 \\
\hline Hypotelorism & - & $2 / 13$ & $2 / 14$ & 14 \\
\hline Epicanthus & + & $9 / 12$ & $10 / 13$ & 77 \\
\hline Depressed/broad nasal base & + & $9 / 17$ & $10 / 18$ & 56 \\
\hline Abnormal auricle & - & $7 / 16$ & $7 / 17$ & 41 \\
\hline Long upper lip & + & $6 / 14$ & $7 / 15$ & 47 \\
\hline Mouth open/drooling & + & $10 / 11$ & $11 / 12$ & 92 \\
\hline High/narrow palate & - & $9 / 14$ & $9 / 15$ & 60 \\
\hline Small chin/micrognathia & + & $13 / 17$ & $14 / 17$ & 82 \\
\hline \multicolumn{5}{|l|}{ Osteoarticular } \\
\hline Hyperlaxity of joints & + & $7 / 12$ & $8 / 13$ & 62 \\
\hline Kyphosis/scoliosis & + & $5 / 14$ & $6 / 15$ & 40 \\
\hline Genua vara recurvata & - & $5 / 12$ & $5 / 13$ & 39 \\
\hline Planovalgus/tarsovalgus feet & + & $6 / 14$ & $6 / 15$ & 40 \\
\hline Other radiographic anomalies & - & $6 / 12$ & $6 / 13$ & 46 \\
\hline
\end{tabular}

4 Verloes A, Journel H, Elmer C, et al. Heterogeneity versus variability in megalocornea-mental retardation (MMR) syndromes: report of new cases and delineation of 4 probable types. Am 7 Med Genet 1993;46:132-7. 